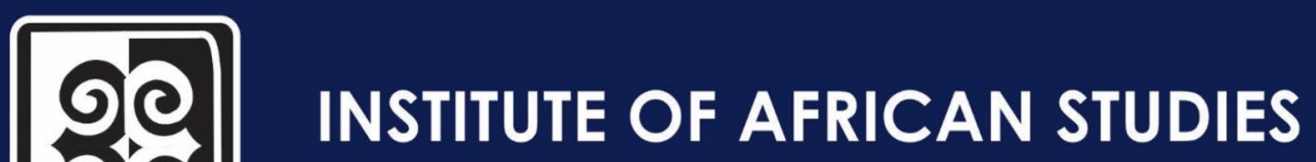 UNIVERSITY OF GHANA
}

Contemporary Journal of African Studies 2020; 7 (2): 45-62

https://dx.doi.org/10.4314/contjas.v7i2.4

ISSN 2343-6530

(C) 2020 The Author(s)

Open Access article distributed under the terms of the

Creative Commons License [CC BY-NC-ND 4.0]

http://creativecommons.org/licenses/by-nc-nd/4.0

\section{Reflexives and Intensifiers in Dagbani and Gurenc}

\section{Samuel Alhassan Issah ${ }^{1}$, Avea E. Nsoh ${ }^{2}$ \& Samuel Awinkene Atintono ${ }^{3}$}

${ }^{1}$ Senior Lecturer, College of Languages Education, University of Education, Winneba

Author's email: samuelissah@yahoo.com

${ }^{2}$ Associate Professor, College of Languages Education, University of Education, Winneba Author's email: ephraimnsoh@yahoo.com

${ }^{3}$ Senior Lecturer, Accra College of Education, Accra

Author's email: satintono@gmail.com

\begin{abstract}
This paper discusses the morphology and distribution of reflexive pronouns and self-intensifiers in two Mabia (Gur) languages of Ghana, Gurene and Dagbani. We show that reflexive pronouns in both languages are bimorphemic, comprising of a personal pronoun and the reflexivizer -mina and -mana 'self', for Gurene and Dagbani respectively. We again, show that self-intensifiers and reflexives are morphologically distinct as the former has additional morpheme -man and $-m /$ for Dagbani and Guren $\varepsilon$ respectively, which we analyse as being responsible for the emphatic readings of self-intensifiers. We also demonstrate that reflexives are invariably in the same clause with their antecedents. We however, contend that unlike Dagbani, the third person emphatic ena 'she/he' and its weak counterpart $a$ 'she/he' are mutually exclusive in Gurenc, explaining why personal names are incompatible with the former. Finally, we demonstrate that adnominal and inclusive intensifiers seem to have similar distribution, suggesting that the Gurene and Dagbani data do not justify the postulation of three subtypes of intensifiers.
\end{abstract}

Keywords: Mabia, Dagbani, Gurene, intensifiers, reflexives, distribution, alternatives, anaphoric 


\title{
Reflexives and Intensifiers in Dagbani and Gurene
}

\author{
Samuel Alhassan Issah, Avea E. Nsoh, Samuel Awinkene Atintono
}

\begin{abstract}
This paper discusses the morphology and distribution of reflexive pronouns and self-intensifiers in two Mabia (Gur) languages of Ghana, Gurene and Dagbani. We show that reflexive pronouns in both languages are bimorphemic, comprising of a personal pronoun and the reflexivizer -mina and -mana 'self', for Gurene and Dagbani respectively. We again, show that self-intensifiers and reflexives are morphologically distinct as the former has additional morpheme $-m a n$ and $-m /$ for Dagbani and Guren $\varepsilon$ respectively, which we analyse as being responsible for the emphatic readings of self-intensifiers. We also demonstrate that reflexives are invariably in the same clause with their antecedents. We however, contend that unlike Dagbani, the third person emphatic epa 'she/he' and its weak counterpart a 'she/he' are mutually exclusive in Gurene, explaining why personal names are incompatible with the former. Finally, we demonstrate that adnominal and inclusive intensifiers seem to have similar distribution, suggesting that the Gurene and Dagbani data do not justify the postulation of three subtypes of intensifiers.
\end{abstract}

Keywords : Mabia, Dagbani, Gurene, intensifiers, reflexives, distribution, alternatives, anaphoric

\section{Résumé}

L'article traite de l'occurrence des pronoms réfléchis et des auto-intensificateurs dans deux langues Mabia (Gur) du Ghana, Gurene et Dagbani. Nous montrons que les pronoms réfléchis dans les deux langues sont

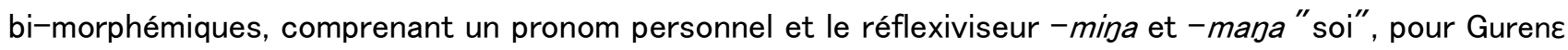
et Dagbani respectivement. Nous montrons aussi que les auto-intensificateurs et les pronoms réfléchis sont morphologiquement distincts, le premier ayant un morphème supplémentaire - man et - $\mathrm{m} /$ pour Dagbani et Gurene respectivement, ce que nous analysons comme étant responsable des lectures emphatiques des auto-intensificateurs. Nous démontrons également que les pronoms réfléchis sont invariablement dans la même clause avec leurs antécédents. Nous soutenons cependant que, contrairement à Dagbani, le pronom emphatique de la troisième personne eja "elle/il" et son homologue faible "elle/il" s'excluent mutuellement dans Gurene, ce qui explique pourquoi les noms personnels sont incompatibles avec la première. Enfin, nous démontrons que les intensificateurs adnominaux et inclusifs semblent avoir une distribution similaire, ce qui suggère que les données de Gurenc et de Dagbani ne justifient pas la postulation de trois sous-types d'intensificateurs.

Mots-clés : Mabia, Dagbani, Gurene, intensificateurs, pronoms réfléchis, distribution, alternatives, anaphoriques

https://dx.doi.org/10.4314/contjas.v7i2.4

Dr. Samuel Alhassan Issah (samuelissah@yahoo.com) is a Senior Lecturer in Linguistics and Indigenous languages at the College of Languages Education, University of Education, Winneba. He holds MPhil in Theoretical Linguistics and PhD in Linguistics awarded by the University of Tromsø, Norway, and Goethe University, Frankfurt am Main, Germany respectively. His research focuses on the syntax of Dagbani and related languages, information structure of Dagbani, the syntax of anaphoric elements, the expression of negation, and the syntax of elliptical phenomena.

Avea E. Nsoh (ephraimnsoh@yahoo.com) is an Associate Professor of Linguistics and Indigenous Studies at the College of Languages Education, University of Education, Winneba. He holds a PhD and M.A in linguistics awarded by the University of Ghana, Legon. His research interests include morphology and syntax, oral literature and culture, Onomastics, literacy, language policy, planning, and language documentation. He is co-author of the Gurene-English Dictionary and Gurene-English Glossary, and Aspects of Oral literature in Ghana with illustrations from selected Languages. He has several other publications to his credit in both local and international journals.

Dr. Samuel Awinkene Atintono (satintono@gmail.com) is a Senior Lecturer in Linguistics and the Principal of the Accra College of Education, Accra. He holds a PhD in Linguistics and MPhil in Linguistics awarded by the University of Manchester, United Kingdom and University of Ghana, Legon, respectively. His research interests include language use in education, linguistic rights of minority or less studied languages, semantics of Gurene and other Mabia languages of Ghana, descriptive, documentary and theoretical (cognitive) linguistics. He has authored several articles, book chapters, and books in both local and international journals. 


\section{Introduction}

The morphological similarity between reflexive pronouns and intensifiers is attested in the literature to be a widespread phenomenon in most natural languages. This morphological characterization of the two anaphoric expressions has been the main parameter that typologists have used in distinguishing the types of languages, as indicated by the World Atlas of Language Structures (WALS: http://wals.info/). This variety of the world's languages has consequently led to the classification of the languages into two types: those in which intensifiers and reflexive pronouns share morphological parallelism, and those in which the two differ morphologically. As Wang (2011) rightly notes, for instance, in a language like English, the self-forms are used both as reflexive pronouns and as intensifiers, indicating that the two share formal morphological properties. However, he further points out that, in contrast to what pertains in the English language, there are other languages in which the reflexive pronouns and intensifiers are formally distinct, and intensifiers can be used to re-inforce reflexive pronouns. This is illustrated in German where in 'sich selbst', sich is a reflexive pronoun, while selbst is an intensifier. Within the past two decades, the relationship and interaction between reflexive pronouns and intensifiers (emphatics) have been of interest in crosslinguistic investigations (cf: Siemund 2000; Konig \& Siemund 2000a). The objective of the current paper is mainly to provide an account of the morpho-syntactic and semantic characterisations of reflexives and intensifiers in two Mabia (Gur) languages: Dagbani and Guren $\varepsilon$, spoken in the Northern region and upper East region of Ghana respectively. ${ }^{1}$

Dagbani and Gurene (Farefari) both belong to the Mabia (Gur) central languages of the Oti-Volta sub-group of languages (Niger-Congo) in northern Ghana (Bodomo 2020; Naden, 1988, 1989; Bendor-Samuel, 1971). Dagbani has three main dialects, namely Tomosili (Western Dialect), Nanunli, and Nayahali (Eastern dialect), which are spoken in and around Tamale, Bimbilla and Yendi respectively (Hudu, 2010; Olawsky 1999). The Dagbani data used in this study are based on the Tomosili dialect, which is the dialect of one of the authors of this paper. Gurene (here understood as the Farefari language) comprises the Boone, Gurene, Nikare, Nabt and Talen dialects (Atintono, 2013; Nsoh, 1997; 2011; Dakubu, 1996; Naden and Schaefer, 1973) and are spoken in towns such as Bongo, Bolgatanga, Siirego, Nangu'ut, and Tong respectively. Farefari is also spoken across the border into southern Burkina Faso. The Guren data for the study is based on the Gurene dialect of two of the authors. It is representative of all three dialects, especially the first three (Boone, Guren and Nikare) with respect to the dialect continuum. The structure of the paper is as follows: a general background to reflexives and intensifiers and the notion of binding principles and c-command are provided first and then followed with a discussion on the distribution of reflexives/selfintensifiers. We go further to explore the properties of reflexive pronouns and self-intensifiers in Dagbani and Guren $\varepsilon$. We also discuss the distribution and interpretation of intensifiers in the two Mabia languages under the same section. Finally, we present the conclusions of the paper.' Intensifiers, reflexive pronouns and the binding theory

Intensifiers and reflexives share formal morphological similarity (have similar forms) in many of the world's languages. Consequently, the assumption in the literature has been that knowledge of intensifiers is crucial in understanding the linguistic characteristics of reflexivity, suggesting that these two anaphoric expressions are better understood if studied in tandem. The focus of this section is to provide the definitions of intensifiers and reflexives, outline the three principles of binding theory, define and provide an illustration of c-command since these concepts are relevant to understanding later discussions in this work.

Moravcsik (1972) first introduced the word intensifier (cf. also Siemund, 2000; Konig, 1991; Edmondson \& Plank, 1978). She defined it based on certain linguistic properties, including their prosodic, syntactic and semantic characterization (http://wals.info/feature/47), based on cross-linguistic considerations. Intensifiers, which are analysed as 'stressed anaphorically dependent element' in light of Constantinou (2013), have been demonstrated in the literature to have three different interpretations including: adnominal, exclusive and inclusive (Constantinou, 2013; Gast, 2006; Eckardt 2001; Siemund, 2000). The data below exemplify these three different interpretations of intensifiers for the adnominal in (1a), inclusive in (1b), and the exclusive in (1c).

(1) a. It wasn't the director's secretary who went to the meeting. The director herself went.

b. Apart from Bill, John has himself built a house, even though he wasn't happy about it.

c. John did not build this house with Bill's help. John built it himself. (Constantinou, 2013: 91).

Working with the assumption that the distributional variation of intensifiers/emphatic reflexives determines their interpretation, Constantinou (2013) accounts for the semantics of these three different intensifiers as shown in (1). Constantinou (2013) proposes that when the intensifier is adjoined to its antecedent as in (1a), it is interpreted as 'in person'. He further notes that when an intensifier immediately follows the auxiliary as in (1b), it

${ }^{1}$ We would like to thank Tony Naden for checking the paper for language. We also acknowledge the comments and suggestions from the two anonymous reviewers of the Contemporary Journal of African Studies (CJAS), which have helped in shaping the arguments in this paper. However, all analytical lapses and errors remain ours. 
has an interpretation similar to additive focus particles (e.g., also), and when the intensifier occurs in the postverbal domain as in $(1 \mathrm{c})$, its interpretation suggests that the action that is denoted by the predicate was "carried out without help' (Constantinou, 2013: 91).

Reflexives are anaphoric elements in the sense that they depend on the determiner phrase (DP) antecedents for their meaning. According to Wang (2011), the most common use of the reflexive pronoun is to show that subject and object arguments have the same referent. Wang (2011) further proposes that because they occur in argument positions, they cannot be omitted.

Notwithstanding the fact that they are characterised to be prominent in argument positions, Wang (2011) also admits that on rare occasions, reflexives do occur in non-argument positions. Adopting a definition of reflexive pronouns based on the World Atlas, Wang (2011:10) contends that: "Reflexive pronouns (for 'reflexive anaphors') are expressions which are prototypically used to indicate that a non-subject argument of a transitive predicate is co-referential with (or bound by) the subject, i.e. expressions like German sich, Russian sebja, Turkish kendi, Mandarin ziji, English $X$-self." He illustrates this with the English example in (2).

(2) They $y_{i}$ wore immaculate clothes, regarded themselves $s_{i}$ as an elite and behaved like gods. [BNC, ARP 38] (Wang 2011:10)

Wang (2011) explains that in the English example in (2) the subject argument they and the direct object themselves are co-referential, in the sense that the referents of the subject and self-form are the same, and target of the predicate 'regarded'. Regarding the distribution, the reflexive anaphor and its antecedent are invariably clause bound, and that the reflexive is obligatory.

The classification of reflexives has generally been based on their distribution; that is, where they pick their reference from within the clause structure. Based on this, reflexives are grouped into two categories in the linguistic literature, labelled as long-distance anaphors and local anaphors (Huang, 2002; Pica, 1987, 1985; Faltz, 1977). According to the authors, whereas non-local antecedents can have long-distance antecedents, the local anaphors require clause-internal syntactic arguments, which serve as antecedents. The possibility of a reflexive pronoun being local or distant has also been associated with their morphological composition, termed as bimorphemic and monomorphemic reflexives. The former as in the English PRO+self only have their antecedents within the same clause, whereas in the latter the antecedent and its anaphoric element can be in different clauses as with the zij of Mandarin Chinese. The claim that the English reflexive pronouns are disallowed in long-distance binding relations is demonstrated in (3a) and (3b). Referring to the data in (3), the distribution and co-referentiality of the reflexive him and himself respectively buttresses the fact that in English the reflexive is only bound to an antecedent in the local domain. This analysis agrees with the standard theory of the classical Binding Theory of (Chomsky, 1981; Carnie, 2013).

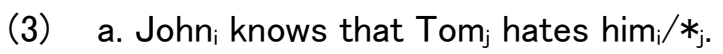

b. John $n_{i}$ knows that $T o m_{j}$ hates himself* $*_{i} /$. (Wang 2011: 89)

Unlike English where long-distance binding is disallowed-and of course in languages like Dagbani and Gurene as we shall soon demonstrate-in Mandarin Chinese, long-distance binding is allowed as shown in (4). This phenomenon of long-distance binding refers to those reflexive pronouns that "have their antecedents outside their governing categories' (Hermon and Huang, 2001). In line with this, it is possible for a reflexive to have its antecedent within the local domain or in the higher clause, i.e. the local subject. This syntactic property of the Mandarin Chinese reflexives according to Wang (2011), often results in ambiguity since it is mostly unclear the exact noun phrase (NP) antecedent the reflexive pronoun actually picks its reference from.

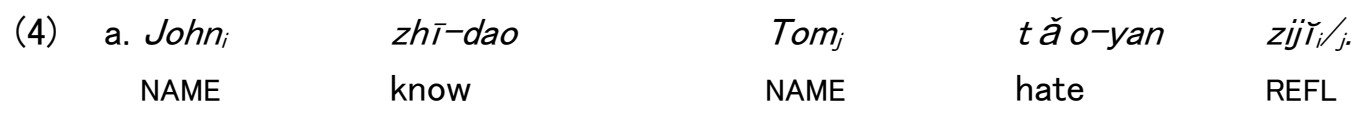

'John knows that Tom hates him/himself.'

$\begin{array}{cllll}\text { b. John } & \text { zhī-dao } & \text { Tom }_{j} & t a ̆ o-y a n & t \bar{a}-z i j i *_{i} / j . \\ \text { NAME } & \text { know } & \text { NAME } & \text { hate } & \text { REFL }\end{array}$

'John knows that Tom hates himself.' (Wang 2011: 89)

As indicated by Wang (2011), when the reflexive pronoun is compounded as in the form $(X-z i j i)$, its distribution is similar to what pertains in English as in (3b) and (4b). In the subsequent discussions, we investigate the linguistic characterisations of reflexives and intensifiers in Dagbani and Gurene.

The syntactic requirements for anaphors (i.e., reflexives and reciprocals) are that they must (i) have antecedents, (ii) agree with the antecedents in number and gender, and (iii) the reflexive (anaphor) must occur in a specific domain. This is variously referred to as the clause-mate condition (old fashioned), binding domain, and governing category. The syntax of anaphoric elements and their antecedents have often been accounted for using 
the binding theory of (Chomsky, 1981; Carnie, 2013.). Of the three classical Binding Principles, it is only Principle A, which captures the relationship of anaphors and their antecedents, which is relevant for our discussion. The other two principles deal with the interpretation of pronouns and referring expressions which are not relevant for this study, and for that matter are not discussed. Here, we discuss the Principle A, as well as broadened to include the definition and illustration of $\mathrm{c}^{-}$-command. Note that in referring to binding domain, it means an anaphor should be within the same clause (specific syntactic domain). The principles labelled as Principle A, B and C are outlined in (5).

(5) a. Principle A: An anaphor must be bound in its binding domain.

b. Principle B: A pronoun must be free in its binding domain.

c. Principle C: An R-expression must be free.

(Carnie, 2013: 157)

Binding also requires a c-command relationship between the anaphoric element and its antecedent (coindexed elements). We thus, deem it important to include the definition and illustration of c-command. Let us consider the data in (6) illustrating the notion of $c^{-}$-command using the illicitness in (6a) versus the grammaticality of (6b).

(6) a. $*[$ Abu's; mother $]$ invited herselfi.

b. [Bonayo's father $]_{i}$ insulted himself

The ungrammaticality of $(6 a)$ is the result of the violation of Principle $A$ of the binding theory, which stipulates that the reflexive pronoun herself should be bound in its binding domain. Since its binder Abu's is embedded inside the DP ${ }^{2}$ Abu's mother, it cannot c-command outside of the DP and therefore cannot bind herself. Thus, in (6a) the entire DP, Abu's mother is the relevant node for ensuring that c-command is not violated and not just Abu's. This is in contrast with its grammatical counterpart in (6b) where the DP Bonayo's father satifies the requirement of $\mathrm{c}^{-}$-command, which is relevant for the realization of Principle $A$ of the binding theory.

As pointed out by Carnie (2013: 157), the notion of binding domain is very salient in the distribution of anaphoric items and their antecedents, since the two should be within the same binding domain. This is exemplified in (7a) for Dagbani and (7b) for Gurene.

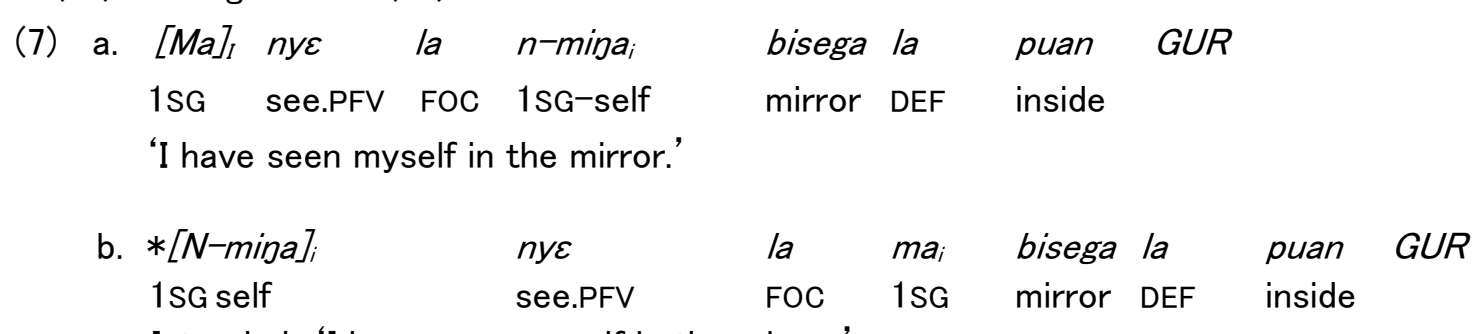

Intended: 'I have seen myself in the mirror.'

c. $[N]_{i}$ nya m-mana ${ }_{i}$ diyi maa ni DGB

$1 \mathrm{SG}$ see.PFV $1 \mathrm{SG}$-self mirror DEF inside

'I have seen myself in the mirror.'

d. *[m-mana $]_{I}$ nya $n_{i}$ diyi maa ni $D G B$

1SG self see.PFV $1 \mathrm{SG}$ mirror DEF inside

Intended: 'I have seen myself in the mirror.'

The grammaticality of sentences $(7 a)$ and $(7 c)$ is borne out of the fact that the reflexive pronouns and their antecedents, $n$ mina and $m$ mana 'myself' for Guren $\varepsilon$ and Dagbani, respectively are found in the same clause (binding/governing domain) with their antecedents, ma and $n$ 'I' as evident in (7a) and (7c). The use of the coreferentiality subscript $;$ ' indicates that the reflexive is bound by its antecedent. It is worthy of note that sentence (7b) and (7d) are ungrammatical because of the violation of Principle A of the binding theory. Although the reflexive and its antecedent are in the same governing domain in (7b) and (7d), the antecedent does not c-command the reflexive.

It is important to further show that when reflexives and their antecedents are co-referential but not in the same governing domain, Principle $A$ is violated, hence yielding ungrammatical sentences. This is illustrated by the ungrammaticality of ( $8 a$ ) for Dagbani and ( $8 b$ ) for Gurene. For instance, in (8a), the reflexive 0 -mana 'herself' and

\footnotetext{
${ }^{2}$ The terms DP and NP are used interchangeably throughout this paper.
} 
its antecedent Azima are not within the same clause, and in (8b), the reflexive a-mina 'herself' is also in a different clause with Azongo, the antecedent. The violation of the locality constraint of reflexives and their antecedents, therefore, results in deriving ungrammatical sentences as shown in (8).
(8)
yeli
Azima say.PFV
a. *Azima
mi ni o-mana
nyela bundana.
FOC that 3sG-self
COP rich person
$D G B$
'Azima has said herself is a rich person.'

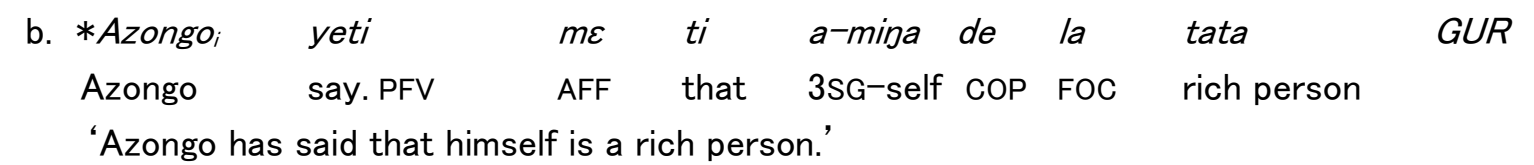

Bodomo (1997: 137-139) also offers an account of locality effects on the distribution of reflexives in Dagaare-a closely related language-and notes that with this language, reflexives and their antecedents are required to be in the same governing domain as shown in the grammaticality of $(9 a)$ and ungrammaticality of (9b).

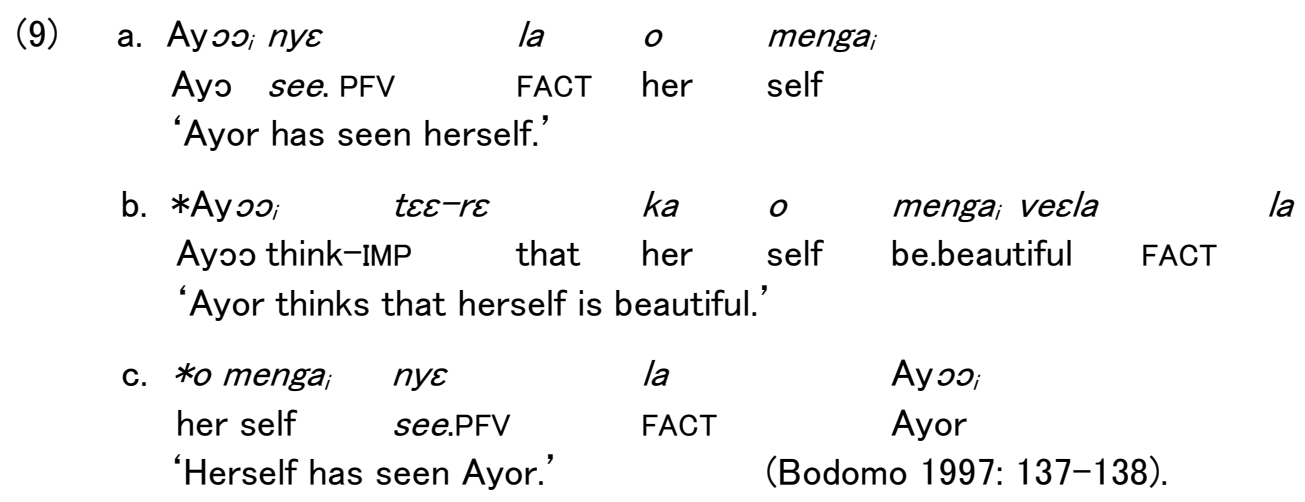

Bodomo (1997) contends that (9a) is grammatical because the reflexive o menga 'himself' and its antecedent Ayor are in the same clause, whereas the illicitness of (9b) is attributable to the fact that the reflexive $o$ menga 'herself' and Ayor (antecedent) are not within the same clause, and for that matter a violation of Principle $A$ of the binding theory. In (9c), although the antecedent and its reflexive are within the same clause, the former does not $c^{-}$ command the latter, the reason for which Principle A is once again violated. This explains why Haspelmath (2019) argues that there are two main requirements that license the grammaticality of reflexive constructions: (i) the two participants of a clause are coreferential, and (ii) that the construction contains a special form (a reflexivizer) that signals this coreference. We have so far shown that, canonically, reflexive pronouns occur in argument positions and depend on a preceding NP, which serves as its antecedent.

\section{The distribution of reflexives/self-intensifiers}

In this section, we focus on the distribution of emphatic reflexives/self-intensifiers. Crucial to our argument is the proposal that the self-intensifier morphemes $-m$ and -man for Guren $\varepsilon$ and Dagbani respectively are syntactically dependent elements. This explains why like reflexives, the intensifier markers are sensitive to locality effects, since they are c-commanded by the reflexive pronouns/nominal items from which they take their reference. In the data that follows in (10), we show that for both Dagbani and Gurene the intensifiers must be c-commanded by a nominal element which serves as an antecedent, that is for Gurene (10a and 10c) and Dagbani (10d and 10f). As evident in the illicitness of $\left(10 \mathrm{~b}\right.$ and $10 \mathrm{e}$ ), when the reflexive pronoun and the intensifier are not in a $\mathrm{c}^{-}$-commanding relationship, it suggests that the required locality requirement is violated, and the resulting structure becomes illicit.
a. $m a-m$ mina

$$
\text { nye }
$$$$
\text { see.PFV }
$$
bisega
mirror
'I myself have seen the mirror.'
b. *ma-m nye bisega la mina.
1SG-INT see.PFV mirror DEF self
Intended: 'I myself have seen the mirror.'

la.
c. $n$ nye bisega la ma-m mina 1SG see mirror DEF 1SG-INTself
'I have seen the mirror myself.'
d. m-man mana nya diyi maa.
1SG-INT self see.PFV mirror DEF
'I myself have seen the mirror.'




\begin{tabular}{|c|c|c|c|c|}
\hline e. $* n$ & nya & diji & maa & $\operatorname{man}$ \\
\hline $1 \mathrm{SG}$ & see.PFV & mirror & DEF & INT \\
\hline
\end{tabular}

Intended: 'I myself have seen the mirror.'

$\begin{array}{llll}\mathrm{f} . & n \text { nya diyi maa m-man } & \text { mana. } \\ \text { 1SG see.PFVmirror DEF 1SG-INT } & \text { self } \\ \text { "I have seen the mirror myself.' } & \end{array}$

It is important to point out that crucially, emphatic reflexives/self-intensifiers may occur in the preverbal slot as in $(10 \mathrm{a})$ and $(10 \mathrm{~d})$, or the postverbal position like (10c) and (10f). In each of these cases, there is a requirement for the emphatic pronoun to dominate the self-intensifiers immediately. The ungrammaticality of (10b) and $(10 \mathrm{e})$, where the intensifiers are not adjoined to the DPs they intensify (they are not immediately dominated by them) is interpreted to mean that, the intensifiers require they are c-commanded by the NPs that they take their reference from, for which reason they are syntactically dependent elements. Given this fact, we conclude that syntactically these reflexive/anaphoric items are sensitive to locality conditions. This is along the syntactic approach of Neeleman \& van de Koot $(2010,2002)$ who contend that self-intensifiers exhibit locality constraints just like reflexives. ${ }^{3}$

To conclude, the reflexive pronouns of Dagbani and Gurene are composed of personal pronouns and selfmorpheme. Syntactically, they are governed by locality constraints/effects, and for that matter are required to be in the same clause in line with the Principle A of binding theory. The self-intensifiers are also sensitive to locality constraints in the sense that, they are required to be in a c-commanding relationship with the nominals that they emphasise. This explains why a derivation is illicit when the two are not adjacent to each other in the syntax. In the section that follows, we explore the characteristics of reflexive pronouns and intensifiers in Dagbani and Gurene.

\section{Properties of reflexive pronouns and intensifiers in Dagbani and Guren}

Previous studies in both languages have delved into the morphosyntax of reflexives (Atintono [2013, 2004] for Gurene, Olawsky [1999] and Issah [2011a] for Dagbani), while intensifiers in both languages remain largely ignored. Although these earlier works on Dagbani and Gurene discuss reflexives, they are rather cursory and do not provide much details. It is not only the case that they are scanty, but also they do not consider a discussion on intensifiers and their possible relationship with the reflexives. Thus, this present analysis does not actually refute earlier works, but complements them by extending the discussion to intensifiers and the possible formal parallelism between the two anaphoric expressions. Crucially, an important and new aspect that is learnt about Dagbani and Gurene is the possible morphosyntactic relationship between reflexives/intensifiers. In this section, we present the linguistic characteristics of reflexive pronouns and intensifiers in Dagbani and Gurene. 'We concentrate on the morphological characterization of the intensifiers and reflexive pronouns in the two languages first and then follow up with a discussion on the syntax and interpretation of intensifiers in Dagbani and Gurene.' We show that distributionally, intensifiers form a syntactic dependency with an antecedent NP and show that there is always a kind of dependency relation between the intensifier and its antecedent.

\section{The morphology of reflexives and intensifiers in Dagbani and Gurene}

Reflexive pronouns and intensifiers, which very often exhibit identical forms, have been of keen research interest (König et al. 2013; Konig et al. 2005). As briefly pointed out earlier, morphological structure constitutes a core component of the characterization of reflexive pronouns. This section takes a closer look at the morphology of reflexives and intensifiers in the two languages. Before we present the tables on the reflexives and intensifiers in Dagbani and Gurene, we first begin with the 'plain pronouns' (non-reflexive forms). This is intended to make it easier for comparison with the reflexive forms. The pronoun paradigm of Dagbani and Guren $\varepsilon$ are presented in Tables 1 and 2 respectively.

\footnotetext{
${ }^{3}$ We are grateful to an anonymous reviewer for pointing out this morphological issue which we seem to have ignored in our comments. Morphologically, it appears that the intensifier (man mana) is derived from the reflexive mana via reduplication. This is in harmony with cross-linguistic observations on reduplication, which shows that reduplication is used to mark intensity, although the Gurene case looks less obvious since it makes use of an independent intensifier morpheme. Thus, it would appear that what is going on here is a morphosyntactic process, not solely syntactic.
} 
Table 1: The personal pronominal paradigm of Dagbani

\begin{tabular}{|c|c|c|c|c|c|c|c|c|}
\hline & \multicolumn{2}{|c|}{ subject forms } & \multicolumn{2}{c|}{ object forms } & \multicolumn{2}{c|}{ emphatic pronouns } & \multicolumn{2}{c|}{ possessive pronouns } \\
\hline Person & singular & plural & singular & plural & singular & plural & singular & plural \\
\hline $1^{\text {st }}$ & $m, n, \eta$ & $t i$ & $m a$ & $t i$ & mani & tiniima & $m, n, \eta$ & $t i$ \\
\hline $2^{\text {nd }}$ & $a$ & $y i$ & $a$ & $y a$ & $n y i n i$ & $y i n i m a$ & $a$ & $y i$ \\
\hline $\left.3^{\text {rd }}{ }_{(\text {ANIM }}\right)$ & $o$ & $b \varepsilon^{4 i}$ & $o$ & $b a$ & puna & bana & $o$ & $b \varepsilon$ \\
\hline $3_{\text {rd }}$ (INAN) & $d i$ & $d i$ & $l i$ & ga & dina & pana & $d i$ & $d i$ \\
\hline
\end{tabular}

Table 2: The personal pronominal paradigm of Gurene

\begin{tabular}{|c|c|c|c|c|c|c|c|c|}
\hline & \multicolumn{2}{|c|}{ subject forms } & \multicolumn{2}{c|}{ object forms } & \multicolumn{2}{c|}{ emphatic pronouns } & \multicolumn{2}{c|}{ possessive pronouns } \\
\hline Person & singular & plural & singular & plural & singular & plural & singular & plural \\
\hline $1^{\text {st }}$ & $m a / n$ & $t u$ & $m a$ & $t u$ & mam & tumam & $m a$ & $t u$ \\
\hline $2^{\text {nd }}$ & $f u$ & $y a$ & $f u$ & $y a$ & $f u m$ & yamam & $f u$ & $y a$ \\
\hline $3^{\text {rd }}$ & $a$ & $b a$ & $e$ & $b a$ & $e n a$ & bamam & $a$ & $b a$ \\
\hline
\end{tabular}

Having outlined the personal pronoun paradigm in Dagbani and Guren $\varepsilon$, we now present the intensifiers and reflexive pronouns of Guren $\varepsilon$ and Dagbani in Tables 3 and 4 below.

Table 3: Gurene reflexive pronouns and intensifiers

\begin{tabular}{|c|c|c|c|}
\hline Reflexive & Gloss & Self-intensifier & Gloss \\
\hline mamina & myself & mam mina & I myself \\
\hline fumina & yourself & fum mina & you yourself \\
\hline amija & him-/her-/itself & ena mipa & s/he him/herself \\
\hline bamisi & themselves & bamam misi & they themselves \\
\hline tumisi & ourselves & tumam misi & we ourselves \\
\hline yamisi & yourselves & yamam misi & you yourselves \\
\hline
\end{tabular}

Table 4: Dagbani reflexive pronouns and intensifiers

\begin{tabular}{|c|c|c|c|}
\hline Reflexive & Gloss & Self-intensifier & Gloss \\
\hline mmana & myself & mman mana & I myself \\
\hline amana & yourself & aman mana & you yourself \\
\hline omana/di-mana & him/her/itself & o/di man mana & he/she/her self \\
\hline bemana & themselves & be man mana & they themselves \\
\hline timana & ourselves & ti man mana & we ourselves \\
\hline yimana & yourselves & yi man mana & you yourselves \\
\hline
\end{tabular}

Different strategies are employed for the derivation of reflexives. For instance, in some languages like Akan, the reflexive is formed with a possessive pronoun + ho, which means 'body' (Saah, 2014; Osam, 2002), whereas Ewe, according to Agbedor (2014), uses a personal pronoun together with the morpheme 'self'. From Tables 3 and 4 , it is evident that reflexives in both languages are, in terms of their morphological structure, derived via the combination of the personal pronouns to the morphemes - self, which is -mina for Guren $\varepsilon$ and -mana for Dagbani. Thus, as in most languages, Dagbani and Gurene have what Haspelmath (2019: 11) calls 'possessive-indexed reflexive nouns', that is the situation in which the 'reflexive nominal looks like a noun that takes adpossessive person forms, so that the literal translation is 'myself', 'yourself', 'himself', and so on.' Huddleston and Pullum (2002:1483) make a similar observation for English and conclude that 'reflexive pronouns are inflectional forms of the personal pronouns, formed morphologically by the compounding of self with another form: $\cdots$ '. These reflexivizers (self-morphemes) have different morphological characterization in these two languages. The morphology of selfintensifiers and reflexive pronouns looks interesting. For instance, whereas the Dagbani self-morpheme (-mana)

\footnotetext{
${ }^{4}$ The use of the front mid unrounded vowel $/ \varepsilon /$ is an orthographic convention. Phonetically, it is the (-ATR) unrounded vowel $/$ /.
} 
does not inflect for number, in Gurene, - mina inflects for number resulting in different self-forms depending on the singularity or plurality of the antecdent. This sensitivity of the Gurenc -mina to the number features of the antecedent is responsible for the difference in bamisi 'themselves' and tumisi 'ourselves' on one hand, and fumipa 'yourself' and mamipa 'myself' on the other hand. This number sensitivity of the Gurenc's different self-forms presents rather an exceptional typological fact of the morphology of reflexives in the Mabia languages, since for most of them the plurality generally is reflected in the personal pronoun and not the self-morpheme. ${ }^{5}$

The pronominal form is much more complex in Gurene's than illustrated because of the noun class and concord system, which is still functional (Nsoh, 1997, 2001, 2010, 2011; Dakubu, 1996). Thus, each noun class has its singular and plural forms as illustrated in Table 5.

Table 5: Gurene pronominal form and noun class

\begin{tabular}{|c|c|c|}
\hline & \multicolumn{2}{|c|}{ Pronominal form } \\
\hline Gender & Singular class & Plural class \\
\hline I & $a$ (class 1) & $b a$ (class 2) \\
\hline II & $k a$ (class 3) & si(class 4) \\
\hline III & $d i($ class 5) & $a$ (class 6) \\
\hline IV & $k u($ class 7) & $t u$ (class 8) \\
\hline V & $b u($ class 9$)$ & $i$ (class 10) \\
\hline
\end{tabular}

What this table means is that each class may inflect for different class prefix depending on the class and number of its antecedent NP. For instance, we have loko kumipa and kuka kamipa because the antecedent NP, loko 'quiver' is a gender IV, class 7 nominal whiles kuka 'chair' is a gender II class 3 nominal. As a result, - mipa 'self' may be prefixed with either ( $\left.k u^{-}\right)$or ( $k a-$. We, however, observe that the $a / b a$ forms, which are [+human], are more widespread because of the gradual breakdown of the class system, allowing for these pronouns to spread to non-human classes.

However, in Dagbani, the number feature of the antecedent is reflected in a corresponding variation in the pronominal form (that is, reflexives have plural forms when the antecedent is plural), but never on the selfmorpheme as in mmana 'myself' versus timana 'ourselves' yimana 'yourselves'. In each of the examples, irrespective of the number features of the antecedent NP, the morpheme -mana 'self' remains morphologically the same.

The self-intensifiers/emphatic reflexives of both languages also have some striking morphological features that require further discussion based on the data in Tables 3 and 4 . Unlike their reflexive counterparts, the intensifiers are multi-word units: a pronoun form, the 'intensification morpheme' (which induces the emphatic reading), and the self-morpheme. In the case of Gurene, intensification may be marked both on the pronoun and on mina 'self'. This morphological account is evident in forms as shown in (11).

(11). a. ma mina 'myself' versus ma-m mina 'I myself'

b. m mana 'myself' versus $m$ man mana 'I myself'

GUR

$D G B$

Regular intensification is marked on the pronominal stems with the suffixes $(-m,-p a, b a$, mam), while the marked ones (double marking) require regular markers and a prefixation of the mipa 'self' with pronouns as shown in Tables 3 and 4.

This account is favoured by the fact that once the morphemes analysed as being responsible for the emphatic readings $-\{-m,-\eta a, b a, m a m\}$ (Guren $\varepsilon$ ) and $-\{m a b\}$ (Dagbani)-are deleted, the structures are deprived of the intensification readings and only interpretable as regular reflexive pronouns. If this morphological account of the structure of intensifiers is adequate for both languages, then it will be right to conclude that the intensifiers appear to be rather more morphologically complex than the reflexive pronouns, especially in the case of Gurene. This is because in each of the two languages, they could be analysed as comprising of a personal pronoun, and syntactically dependent morphemes that provide the 'intensification property' reading, followed by the selfmorpheme (reflexiviser). We, therefore, contend that the emphatic interpretation is licensed by reduplication of the reflexiver-mana. Given our proposal that the intensifier (man mana) is derived from the reflexive mana via reduplication, we assume that there is a deletion of the /a/ vowel in this morphological process of reduplication.

${ }^{5}$ Although we do not pursue the origin of plural marking in Guren $\varepsilon$ self-forms further, we contend that it is similar with plural marking in our nominal words. 
On the motivation for the deletion of a final vowel in the reduplicant resulting in man-mana, rather than manamana, we assume that it is due to phonological restrictions on the prosodic size of the reduplicant, which requires that it should be bimoraic, that is, a long vowel (CVV), two light syllables, (CV.CV) or a (CVN) syllable (Issah, 2011b). The fact that the morpheme that induces the emphatic reading is a reduplicated segment is not surprising since reduplication is often associated with emphasis in most natural languages. In the literature of reduplication too, it is known that the reduplicant can be a heavy syllable as reported in Mokilese of progressive reduplication (Blevins, 1996:523; Harrison, 1973).

Given this morphological account that certain morphemes (i.e. $-m$ and $-m a n$ ) are responsible for the transformation of reflexives into intensifiers, one would expect, for instance, that if this analysis is correct, (i) these morphemes will appear in different contexts and perform the same function and (ii) the emphatic reading should be absent once these morphemes are deleted and results in illict sentences in the derivation of emphatic constructions. This prediction is borne out, given the fact that the absence of these morphemes deprives a sentence of an emphatic interpretation and results in ungrammatical structures as illustrated in (12b) and (13b) for Guren $\varepsilon$ and Dagbani respectively. ${ }^{6}$

\begin{tabular}{|c|c|c|c|}
\hline $\begin{array}{l}m a-m \\
1 \mathrm{SG}-\mathrm{INT}\end{array}$ & $\begin{array}{l}\text { mina } \\
\text { self }\end{array}$ & $\begin{array}{l}n y \varepsilon \\
\text { see.PFV }\end{array}$ & $\begin{array}{l}\text { gono } \\
\text { book }\end{array}$ \\
\hline
\end{tabular}

'I myself have seen the book.'

b. *ma mina nye gono la.

GUR

$1 \mathrm{SG}$ self see.PFV book DEF

'Intended: I myself have seen the book.'
c. ma nye gono la m-mina.
$1 \mathrm{sg}$ see.PFV book DEF 1SG.INT-self

'I have seen the book myself.'

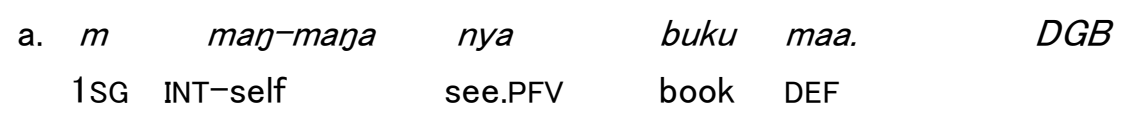

'I myself have seen the book.'

$\begin{array}{lllllll}\text { b. } & * m \text { mana nya } & \text { buku maa. } & \text { DGB } \\ \text { 1SG self see.PFV } & \text { book DEF } & \\ \text { 'Intended: I myself have seen the book.' } & & \\ \text { c. } n & \text { nya } & \text { buku maa } & m & \text { man-mana. } \\ & \text { 1SG see.PFV } & \text { book } & \text { DEF } & 1 \mathrm{SG} & \text { INT-self }\end{array}$

'I have seen the book myself.'

The grammaticality in (12a) and (13a) versus the ungrammaticality in (12b) and (13b) is borne out of the requirement that the intensifier morphemes are required to immediately follow the personal pronouns in the illicit sentences in (12b) and (13b) to licence grammaticality. Readers should recall that reflexives generally require antecedents within a sentence structure to be grammatical. If the intensifier morphemes are removed, the resulting morphological forms are reflexives, which are syntactically disallowed from occurring in the subject position. Given this proposed morphological account, the prediction is that the presence or absence of intensifiers should affect the grammaticality of a sentence as well as its semantic interpretation. Thus, it may seem superficial to assume that self-intensifiers and reflexives are morphologically similar. Given this piece of morphological evidence of an independent morpheme, that is potentially analysable as being responsible for the emphatic interpretation of intensifiers, we assume that the lexical item as a whole is not what induces this interpretation. Consequently, we conclude that Dagbani and Guren $\varepsilon$ have specific morphemes responsible for emphatic readings, rather than the distribution/information structure of the relevant expression. ${ }^{7}$ Considering the morphological forms of the two anaphoric expressions, there is language-internal evidence suggesting that Dagbani and Gurene fall into the category/class of languages in which the two differentiate morphologically. Thus, Dagbani and Guren $\varepsilon$ are unlike

\footnotetext{
${ }^{6}$ We are grateful to an anonymous reviewer for pointing out that this morphological fact serves as a piece of evidence in support of an analysis that contends that, the intensifiers are derived from the reflexive forms and that we can talk about the 'intensive' use of reflexives. Thus in our analysis, 'intensifiers' are treated as reflexive pronouns with an emphatic use.

${ }^{7}$ We do admit that for now, we are unable to establish the occurrence of these morphemes in other syntactic/morphological contexts with similar effects, which probably only suggests that they are limited in distribution.
} 
Likpakpaanl (Acheampong, 2015; Acheampong et al., 2019) in which no specific morpheme is responsible for emphatic readings, but instead the distribution/information structure of the relevant expression. In Likpakpaanl, however, there is always a requirement for an overt focus marker, which must be c-commanded by the selfreflexive. This explains the illicitness of the Likpakpaanl in (14b) and (14d).

(14) a. $\min \quad m$-bà lè bè

1SG.EMPH 1SG-self FOC know 2SG

'I myself identified them.'

b. *min bè̀ bì

1SG.EMPH 1SG-self know 2SG

Intended: 'I myself identified them.'

c. nimi nì-bà lè bàn n-nyok.

2PL.EMPH 2PL-self FOC want medicine

'It is you yourselves who need medicine.'

d. *nimi nì-bà bàn n-nysk

'You yourselves who need medicine.' (Acheampong et al. 2019:138)

In Likpakpaanl therefore, the focus marker lè is what is required to trigger an emphatic reading and not a special morphological item that occurs with the pronominal element as seen of Dagbani and Gurene. To summarize this section, we have given an account of the morphology of reflexive pronouns and intensifiers in Dagbani and Gurene. Whereas the self-morpheme in Gurene inflects for the number features of the antecedent DP, in Dagbani, this is reflected in the personal pronoun number, which explains why the pronoun may vary in form, depending on the number features of the antecedent. The empirical material presented indicates that reflexives are complex, comprising of personal pronominal and a suffix, referred to as a reflexiviser. The intensifiers and reflexives however, do not exhibit formal morphological similarity, motivating a proposal that typologically; they belong to the category of languages in which these two anaphoric expressions are morphologically distinct. In the subsequent discussions, we account for their syntactic and semantic characterizations.

\section{Distribution and interpretation of intensifiers in Dagbani and Gurene}

This section focuses on the distribution and interpretive characteristics of intensifiers in Dagbani and Gurene based on the categorization of intensifiers by Constantinou (2013, 2014) and Eckardt (2001). Before presenting the Dagbani and Gurene data, we repeat Constantinou's data and analysis here for convenience. This will refresh the mind of the reader who may not be familiar with the analysis he proposes. Thus, the data presented in (1) is repeated here as (15).

(15) a. It wasn't the director's secretary who went to the meeting. The director herself went.

b. Apart from Bill, John has himself built a house, even though he wasn't happy about it.

c. John did not build this house with Bill's help). John built it himself. (Constantinou 2013: 91).

As pointed out already in section 2, the data exemplify the three different interpretations of intensifiers for the adnominal in (15a), inclusive for (15b) and the exclusive in (15c). Based on the semantic account of Constantinou (2013: 91), when the intensifier is adjoined to its NP antecedent as in (15a), it is interpreted as 'in person', whereas when an intensifier immediately follows the auxiliary as in (15b), its interpretation is similar to additive focus particles (e.g., also), and finally, when the intensifier occurs in the post-verbal domain as in (15c), it is interpreted to mean that the action denoted by the verb is 'carried out without help'. The classification of intensifiers into adnominal, inclusive and exclusive is attributable to their semantics and distribution. 'We discuss adnominal intensifiers first, followed by inclusive intensifier and finally, we explore the exclusive intensifier.' Crucial in the discussion is the claim that the adnominal and inclusive versions have similar distribution in the languages under investigation, based on the data provided. In addition, we further show that the emphatic pronoun is incompatible with personal names. Accordingly, whenever the NP that c-commands the self-element is a personal name, the reflexive pronoun a-mina 'himself' is used rather than the emphatic form, ena mina 'he himself.' This accounts for the grammaticality of structures like Azure a-mipa 'Azure himself' versus ungrammaticality of *Azure epa mipa 'Azure himself.' 8

\footnotetext{
${ }^{8}$ It is worthy of mention that this observation appears to be solely for Guren and that no such thing pertains in Dagbani based on data we used.
} 


\section{The adnominal intensifiers}

Based on the discussion on the distributional and semantic interpretation of intensifiers in section 2, this section outlines the categories as available in the literature on the study of intensifiers. As argued by Gast (2006), Eckardt (2001), Siemund (2000), and Constantinou (2013, 2014), when the intensifier morpheme is adjoined to its antecedent as in the case of the adnominal interpretation of reflexive intensifiers, as indicated in (16) for Dagbani and Guren $\varepsilon$ (17), the structure is paraphrased 'loosely' as 'in person' (cf: Constantinou 2013, 2014).

(16) a

\begin{tabular}{|c|c|c|c|c|c|}
\hline$\left[_{\mathrm{NEGP}} P_{c}\right.$ & a [NP waasimani & maa] & {$[n$} & [vp sayim & dunoyorigu \\
\hline NEG & security man & DEF & FOC & spoil.PFV & gate \\
\hline maa & {$[\mathrm{TP}[\mathrm{NP}$ kpiema } & $\operatorname{maa}_{i}$ & $\operatorname{man}-$ & gמa [FocP $n$ & [sayim li.] DGB \\
\hline DEF & boss & DEF & INT-s & fFOC & V 3SG.INAN \\
\hline
\end{tabular}

'It isn' $t$ the security man who has spoilt the gate. The boss himself has spoilt it.'

b. [NEGP $* P a\left[\mathrm{NP}\right.$ waasimani maa [FocP $n_{\mathrm{NVP}}$ sayim [NP dunoyorigu $_{\mathrm{NP}}$ NEG security man DEF FOC spoil.PFV gate

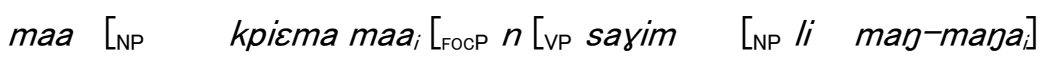

DEF bosss DEF FOC spoit 3SG.INAN INT-self

Intended: 'It isn' $t$ the security man who has spoilt the gate. The boss himself has spoilt it.'

c. $\left[_{\mathrm{NEGP}} P a\left[_{\mathrm{NP}}\right.\right.$ waasimani maa $\quad \mathrm{F}_{\mathrm{FoCP}} n \quad[\mathrm{VP}$ di sayim[NP dunoyorigu

NEG securityman DEF FOC PST spoil.PFV gate

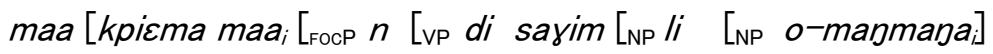

DEF boss DEF FOC PST spoit 3SG.INAN 3SG-INT-self

Intended: 'It wasn' $t$ the security man who spoilt the gate. The boss himself spoilt it.'

(17)

\begin{tabular}{|c|c|c|c|c|c|c|c|}
\hline - $\quad\left[_{\text {NEGP }} L a\right.$ & dagi & [NP wasemaani l & la & $n[\mathrm{vP}$ & sagum & [NP kulena & la \\
\hline It & NEG & security man & DEF & FOC & spoil & door & DEF \\
\hline$[\mathrm{NP} k \varepsilon$ & $\varepsilon m a_{i} l a$ & ${ }_{\mathrm{NP}}$ epa-mina & [FocP & $n[\mathrm{VP}$ & sagum & {$[\mathrm{NP} e / \mathrm{ka}]$} & GUR \\
\hline boss & DEF & 3SG.EMPH-self & FOC & spoil & & 3SG.INAN & \\
\hline
\end{tabular}

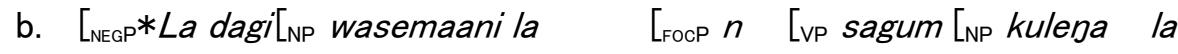

$\begin{array}{lllllll}\text { It } & \mathrm{NEG} & \text { security man } & \mathrm{DEF} & \mathrm{FOC} & \text { spoil } & \text { door DEF } \\ \text { [NP } k \varepsilon^{\prime} \varepsilon m a \text { la }_{i} & \text { [VP sagum } & \text { [NP } e & & \text { [NP } & \text { pa-minai] GUR } \\ \text { boss } & \mathrm{DEF} & \text { spoil } & \text { 3SG.INAN } & & \text { INT-self }\end{array}$

Intended: 'It wasn' $t$ the security man who spoilt the gate, the boss himself spoilt it.'

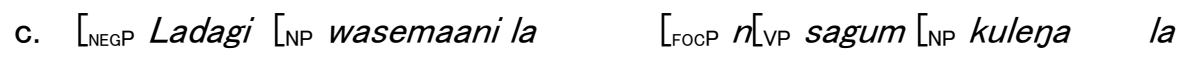

It NEG security man DEF FOC spoil door DEF

[NP $k \varepsilon^{\prime} \varepsilon m a l a_{i} \quad[\mathrm{FocP} n \quad[\mathrm{vP}$ sagum $\quad[\mathrm{NP} e / k a[\mathrm{NP}$ ena mina $] \quad$ GUR

boss DEF FOC spoil 3SG.INAN 3SG.EMPH self

'It wasn' $t$ the security man who spoilt the gate, the boss himself spoilt it.'

The grammaticality of $(16 c)$ and $(17 c)$, buttresses the argument that the self-intensifiers need to be attached to an appropriate antecedent. This is because the intensifiers are by nature anaphoric since they require preceding NPs on which they depend for their meaning. This is in line with our proposal that intensifiers just as reflexives are syntactically dependent variables. This account is further buttressed when we consider the fact that in instances that intensifiers occur in the post-verbal position (after the verb), there is the need for a pronominal element within that syntactic position, and that this pronoun must have a preceding NP as its antecedent. This explains why (16b) and (17b) are ungrammatical since there are no pronouns that precede man-mana as required of Dagbani and mipa for Guren $\varepsilon$. When we consider their grammatical counterparts in (16c) and (17c), the third singular personal pronouns: $o$ 's/he' for Dagbani and $e / k a$ ' $s /$ he' for Guren $\varepsilon$ are required to be in a ccommandaing relationship with the self-intensifiers. $k a$ is the Gender II pronoun, agreeing in number and gender with kulena 'door' (see Table 5). This suggests that a post-verbal intensifier as in English can also encode the adnominal reading of the intensifier, although for Dagbani and Gurene, a pronoun referent to the subject DP is basegenerated and it immediately dominates the self-intensifier. Following the proposal by Gast (2006), Eckardt (2001), and Siemund (2000) on the semantics of adnominal intensifiers-we assume that the contribution of the adnominal 
intensifier, as in the examples above, to the meaning of the sentences is that it establishes an alternative referent (the security man) as being peripheral compared with the antecedent of the intensifier boss'.

The above explanation of the semantics of adnominal intensifiers explains the motivation for the analysis that they have an 'in person' reading. In addition, they generally produce a set of alternative referents to their antecedents. Following a proposal made by Constantinou $(2013,2014)$ on the discussion of the semantics of English adnominal intensifiers, we contend that the alternative referents must be readily available in prior discourse. Now, given the context in (16) and (17), the 'security man' is peripheral to his boss who is the administrative head. This yields a scenario of an interaction between central (the boss) and peripheral (the security man) arguments. Given a scenario in which the contextual assumption that the 'security man' is peripheral within the administrative setting is removed, then the adnominal reading is impossible. This leads to the conclusion that one requirement for the adnominal interpretation of intensifiers is the availability of an argument that is a central referent, and one that is peripheral. In the next subsection, we discuss the inclusive intensifiers.

\section{The inclusive intensifier}

Unlike the adnominal form discussed in the preceding subsection, Constantinou $(2013,2014)$ demonstrates that the inclusive intensifier can be paraphrased via the use of the additive focus particle (e.g. the additive particle also). One syntactic property of this category of intensifiers in Dagbani and Gurene, which is worthy of note, is that they are unlike their English counterparts in terms of distribution, since they do not immediately follow auxiliary verbs. This apparent syntactic characterization is attributable to the fact that neither Dagbani nor Gurens has a productive auxiliary verb system, as it is the case of the English language. The argument that is proposed and predominant in the semantic interpretation of inclusive intensifiers is the assertion that the salient alternative in the discourse must be true (cf: Gast, 2006). Precisely, for the additive effect to be coded, then, the alternatives must be understood to be true.

A shown in the example (18), we provide English examples to help the readers better understand what the inclusive intensifier is, before they encounter the Dagbani and Gurene data. Similarly to the adnominal and exclusive intensifiers, the inclusive intensifier induces alternative referents to its antecedent. An example is provided in (18).

a: Bill has raised three kids.

b: John has himself raised three kids, and he said that it was hard. (Constantinou 2014: 109).

The proposition in (18b), which illustrates the use of an inclusive intensifier suggests that, aside John, there is another referent within the discourse setting that has also raised three kids, and that is of course Bill. Owing to this interpretation, Constantinou (2014: 109) contends that the sentence (18b) is infelicitous when the appropriate preceding discourse is not available. Thus, it might not be in an 'out of the blue context'.

The additive interpretation that is proposed for the inclusive intensifier does not hold for the adnominal and exclusive instances, which allow for the negation of alternatives. This additive semantics is what allows for the possibility of replacing the intensifier with an additive particle (such as also), and that does not result in any significant change in meaning.

a: Bill has raised three kids.

b: John has (also) raised three kids, and he said that it was hard.

We illustrate the use of inclusive intensifiers in example (20). In the case of the example below, the assumption is that $A b u$ and Baba, for Dagbani as well as Azongo and Atibiri, for Gurene should have bought houses; otherwise, there is no additive interpretation of the sentences in this context.

\begin{tabular}{|c|c|c|c|c|c|c|c|}
\hline $\begin{array}{l}\text { a. Abu nuu yi yi, } \\
\text { Abu hand if leave }\end{array}$ & $\begin{array}{l}\text { Baba } \\
\text { Baba }\end{array}$ & $\begin{array}{l}n \\
\text { foc }\end{array}$ & $\begin{array}{l}\text { lan } \\
\text { again }\end{array}$ & $\begin{array}{l}d a \\
\text { buy }\end{array}$ & $\begin{array}{l}\text { yili palli } \\
\text { house new }\end{array}$ & & \\
\hline$*(o)^{9}-m a n-m a n a$, & amaa & 0 & & bi & $z a n$ & gme & 1yoy \\
\hline 3SG-INT- self & but & 3 sg. & & neg & take & knock & chest \\
\hline
\end{tabular}

'Apart from Abu, it is Baba who has (also) bought a new house himself but he is boasting about it (not happy about it).'

b. Fu san base Azongo yire If you

la, Atibire me $n$ le da'

yi-paale a leave Azongo house DEF, Atibire also FOC again buy house-new 3SG self although not beating a nyu'o GUR 3SG chest. 
'Apart from Azongo's house, it is Atibire who has (also) bought a new house himself but he is not boasting about it.'

In (20), the speaker is expected to be certain of the truth conditions of both predicates. This is to mention that, in the case of (20b), the speaker must be sure that both Azongo and Atibire have built houses. Although it is suggested in Constantinou $(2013,2014)$ that in the inclusive usage of intensifiers, the intensifiers are adjoined to the auxiliary verb (at least in a language like English); but in Gurene and Dagbani, such an analysis is not viable. They rather are adjoined to a kind of pronominal (antecedent). This we interpret to mean that a post-verbal intensifier can also encode the inclusive reading of the intensifier just as argued in English. However, the pronoun must always take its reference from a preceding NP and agree in number and animacy features. This further buttresses our analysis that self-intensifiers are syntactically dependent elements in Gurene and Dagbani.

In addition to the additive characterisation of the inclusive intensifier, the Guren $\varepsilon$ and Dagbani data also support the typological claim that the intensifiers of this category are mostly subject arguments. This is expected, given that in SVO languages there is always the tendency of interpreting subjects to be topics (see for instance, Givòn [1976] for this account). To elaborate the proposal that these items can only co-refer with the subject, we illustrate with the ungrammaticality of (21c) and (22c), in which they are unable to co-refer with the object.

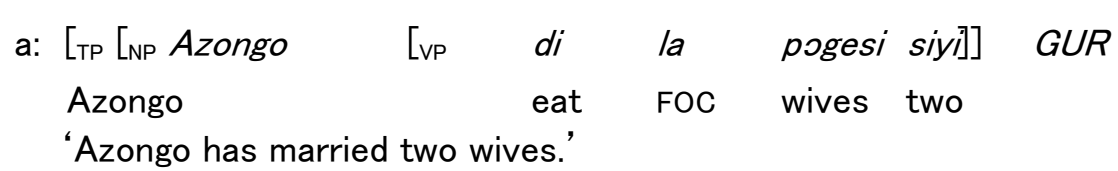

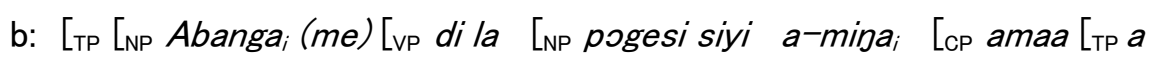

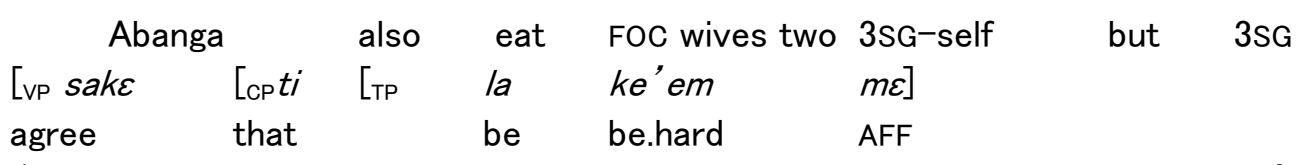

'Abanga has (also) married two wives himself, but he admitted that it was hard.'

c: $\left[\mathrm{TP}\left[\mathrm{NP} *\right.\right.$ Abanga $_{i}$ (me) [vp di la [Np pogesi siyi ba-mam misi

$\begin{array}{llllll}\text { Abanga also eat } & \text { FOC } & \text { wives } & \text { two } & \text { 3PL-INT-selves } \\ \text { [CP amaa [TP a sake } & {[\mathrm{CP}} & t i & \text { [TP la ke' em } \mathrm{m \varepsilon}] \\ \text { but agree } & \text { that } & \text { be } & \text { be.hard AFF }\end{array}$

'*Abanga has (also) married two wives themselves, but he admitted that it was difficult.'

(22)

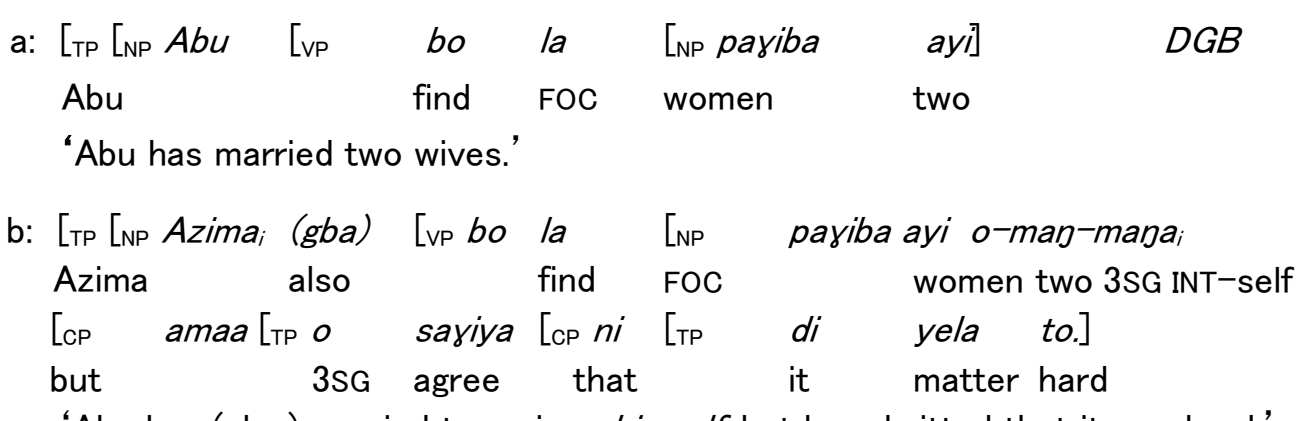

'Abu has (also) married two wives himself, but he admitted that it was hard.'

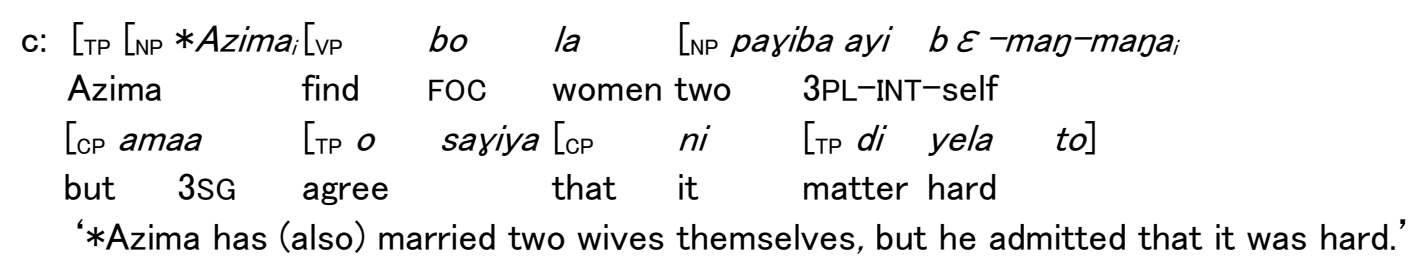

What is apparent in the data provided in (21) and (22) is that, the antecedent of the intensifier is a switch topic (see also Gast [2006] for similar conclusions). For instance, in (21a), the speaker makes an utterance about a topic Azongo, and in the response of speaker "B", there is a shift on this topic to another topic named Abanga. This shift generates the inclusive interpretation, showing that the statement is not only true of (21a), but also (21b). In such a context, (21b) becomes inclusive in the claims made for (21a).

The final characteristic of inclusive intensifiers is the fact that they centralize their antecedents against other referents. Siemund (2000) first identified this property. Gast (2006: 152) notes this when he points out that "in all $[\cdots]$ occurrences of inclusive SELF, we can sense the notion of centrality". Accordingly, a removal of proposition in (21b) and (22b) renders the inclusive interpretation impossible. As Constantinou (2014) notes, it is even more remarkable to realise that the proposition must necessarily be seen as expressing something about the nominal content on which the intensifier is dependent (its antecedent). Going by this deduction, it predicts that the 
inclusive intensifier interpretation is not allowed in a sentence as in (22b) if it expresses something about the speaker (e.g, but I think it is hard to marry two wives). This is irrespective of the fact that the preceding premise may still maintain its status as a premise. Following proposals made by Constantinou (2014), Gast (2006), and Siemund (2000), we assume that this results from a kind of specific relationship between the antecedent and the event that is denoted in the preceding discourse. This assumed relation is not the event-internal (thematic) type, as it is with the exclusive intensifier. This is because the manner in which the event in (21a) and (22a) (i.e. marrying of two wives) takes place is not influenced by (21b) and (22b). This is what leads Constantinou (2014: 95) to hypothesise that 'the inclusive INT centralizes its antecedent against other referents in an event-external manner.'

Given the proposals so far made, it is right to conclude that in example (22) for instance, the event 'external-relation' that is present between Abanga and that of "marrying two wives" centres basically on the difficulty of marrying two wives as perceived by Abanga. Since the extent of the difficulty does not affect the event at issue, we conclude that the relation is indeed 'event-external'. This explains why there is a degradation in contextual felicity when both arguments are in the same point of the scale of difficulty as in (23) and (24).

$\begin{array}{llllll}\text { a: } A b u \text { bo la } & \text { payiba ayi } & \text { ka sayi ni } \\ \text { Abu find } & \text { FOC women two } & \text { and say that } \\ \text { di } & \text { yela to. } & D G B & & \\ \text { 3SG.INAN } & \text { matter hard } & & \end{array}$

'Abu has married two wives but has said that it is difficult to do.'

$\begin{array}{lclll}\text { b: Azima } & \text { man-mana bo la payiba ayi ka sayi } \\ \text { Azima } & \text { INT-self find } & \text { FOC women two } & \text { and agree } \\ \text { ni } & \text { di yela to. } & \text { DGB } & & \\ \text { That 3SG.INAN } & \text { matter hard } & & \end{array}$

'Azima has (also) married two wives himself and seen it is a difficult thing to do.'

$\begin{array}{llllll}\text { Azongo a-mina dil } & \text { a pogeba bayi amaa a } \\ \text { Azongo 3SG-self eat } & \text { FOC wives two CONJ 3SG } \\ \text { sake ti yele toi } & m \varepsilon & \text { GUR } & & \\ \text { agree that matter hard } \mathrm{AFF} & & & \end{array}$

'Azongo has married two wives but he agrees that it is difficult thing to do.'

$\begin{array}{llllllll}\text { b: Abanga a-mina } & \text { di la } & \text { pogesi siyi, amaa a } & \text { sake } \\ \text { Abanga 3SG-self } & \text { eat DEF } & \text { wives two CONJ 3SG } & \text { agree } \\ \text { ti yele la } & \text { toi } & m \varepsilon \text { GUR } & & & \\ \text { that matter DEF } & \text { be.hard } & \text { AFF } & & & \end{array}$

'Abanga has himself married two wives and also seen it equally a difficult thing to do.'

The fact that self-intensifiers are always focused/stressed means that intensifiers have an informationstructural property that enables them to evoke alternatives to the antecedent NP they are bound to (depend on for their interpretation), within a discourse. This assumption is in consonance with the conclusion drawn by Constantinou (2013) who also points out that despite the varied semantic interpretations of the various forms and categories of intensifiers, they are analysable as being related in the English language. Eckardt (2001: 382) also concludes that an intensifier "is obligatorily stressed because it needs to be in focus [or more generally IS-marked] because only in focus will it contribute to the meaning of the sentence" via the inducing of alternatives. We therefore conclude that the adnominal and inclusive versions seem to have similar distribution, at least based on a comparison of the data we provide.

In summary, we have shown that the inclusive intensifiers in the languages under study centralize their antecedents against other referents, imply additivity, and also the antecedent is always a subject and switch topic.

\section{The exclusive intensifier}

Another usage of the intensifier is for the coding of 'exclusion', termed as the exclusive intensifier. In the data in (25a) for Dagbani and (25b) for Gurenc, we exemplify the exclusive usage of intensifiers.

$\begin{array}{lllllllll}\text { a:. Pa Azima paya } n & \text { son } & 0 & k a & 0 & d a & \text { loori } \\ \text { NEG Azima wife } & \text { FOC } & \text { help } & \text { 3SG } & \text { CONJ } & \text { 3SG } & \text { buy lorry } & \text { lorr } \\ \text { maa Azima man-mana } & *(n) & d a & \text { li. } & & \text { DGB } & \end{array}$


DEF Azima INT-SELF FOC buy 3SG.INAN

'Azima did not buy the car with the help of his wife. Azima bought it himself.'

$\begin{array}{llllllll}\text { b: Dagi Abanga poga } & n & \text { supe } & e & \text { ti } & a & d a^{\prime} \\ \text { NEG Abanga wife } & \text { FOC help } & 3 S G & \text { to } & 2 S G & \text { buy } \\ \text { loore la, Abanga } & \text { a-mipa } *(n) & d a & e & \text { GUR } & \\ \text { car DEF Abanga } & \text { 3SG -self } & \text { FOC } & \text { buy } & \text { 3SG } & \end{array}$

'Abanga did not buy the car with the help of his wife. Abanga bought it himself.'

An obvious contribution of the exclusive intensifiers in (25) is for the negation of the alternative versions of the same events in which the subject arguments Azima and Abanga have not received the help of their wives in buying a car. This negation property justifies the 'exclusive' tendency of the intensifier in this context. However, the antecedents are involved in the negated alternatives that are described in the data under (25). This distinguishes the adnominal intensifier discussed in the preceding section from the exclusive intensifier.

Precisely, there is the requirement that, the antecedent in the alternative must invariably be the subject argument (agent), and that the excluded referent must be the helper NP. In the sentences above, the subject arguments are Azima and Abanga for (25a) and (25b), whereas the helper NPs are Azima paya 'Azima's wife' for (25a) and Abanga poga 'Abanga's wife' in (25b). Accordingly, when there is a reversal of the roles of these two referents-while even keeping the same antecedents-the resulting structures yield an infelicitous use of exclusive intensifier as evident in (26).

$\begin{array}{lllllllll}\text { a. \#Pa } & \text { Azima paya } n & \text { son } & o & k a & 0 & d a & \text { loori } \\ \text { NEG } & \text { Azima wife FOC } & \text { help } & \text { 3SG } & \text { CON } & \text { 3SG } & \text { buy } & \text { lorry } \\ \text { maa } & \text { Baako man-mana } & *(n) & d a & \text { li. } & \text { DGB } & & \\ \text { DEF } & \text { Baako INT-SELF } & \text { FOC } & \text { buy } & \text { 3SG.INAN } & & \end{array}$

'Azima did not buy the car with the help of his wife. \#Baako bought it himself.'

\begin{tabular}{|c|c|c|c|c|c|c|c|c|}
\hline & a poga & $n$ & \multirow{2}{*}{$\begin{array}{l}\text { supe } \\
\text { help }\end{array}$} & \multirow{2}{*}{$\begin{array}{l}e \\
3 S G\end{array}$} & \multirow{2}{*}{$\begin{array}{l}t i \\
\text { to }\end{array}$} & \multirow{2}{*}{$\begin{array}{l}a \\
2 S G\end{array}$} & \multirow{2}{*}{$\begin{array}{l}d a^{\prime} \\
\text { buy }\end{array}$} \\
\hline NEG & $A b$ & 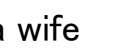 & FOC & & & & & \\
\hline 00 & la. & Azure & $a-m i n$ & & $*(n)$ & $d a$ & $e^{g}$ & GUR \\
\hline car & DEF & Azure & $3 \mathrm{SG}-$ & & FOC & buv & $2 \mathrm{co}$ & \\
\hline
\end{tabular}

'Abanga did not buy the car with the help of his wife. \#Azure bought it himself.'

By reversal of roles in this context, we mean the change in the subjects of the two sentences. For instance, the infelicitous sentences in (26a) and (26b) are different subjects for the negative polarity clauses "pa Azima paya' and 'Baako man-mana' for (26a) and 'dagi Abanga poga' and 'Azure a-mina' for (26b). As shown in (26), the sentences are infelicitious because the antecedents Baako man-mana 'Baako himself' and Azure a-mipa 'Azure himself" are not somewhat involved in the negated version of the event. They are, therefore, new variables that have been introduced into the discourse. In line with previous findings on exclusive intensifiers, (Siemund, 2000, Constantinou, 2013, 2014, Haspelmath 2019), we contend that Dagbani and Gurene also provide evidence for the centrality of antecedents in the interpretation of the exclusives. This is because it is not possible to change the position of the antecedents without corresponding contextual infelicity of the exclusive interpretation of the intensifiers. Given the proposal that the antecedent within the exclusive intensifier must be somewhat involved in the negated version of the event, the scale of centrality is an event internal property, (Constantinou 2013, 2014). We then conclude that a key function of the exclusive intensifier is to centralise its antecedents in opposition to other event-internal elements.

\section{Conclusion}

The present study has focused on the morphology, interpretive and distributional properties of self-intensifiers and reflexive pronouns in Dagbani and Gurenc. We have demonstrated that in both languages, the reflexive pronouns take adpossessive person forms, comprising of the personal pronoun and the reflexivizer - mipa for Gurene and mana for Dagbani. Syntactically, we have shown that the antecedent is always required to precede the reflexive pronoun, suggesting that the former must 'be higher on the rank scale than the latter' as argued by Haspelmath (2019). The emphatic reflexives (self-intensifiers) displayed distinct morphology since they have a form of emphatic morpheme $-m / m a m / e n a$ and -man for Gurene and Dagbani respectively. Both reflexive pronouns and emphatic reflexives (self-intensifiers) are dependent elements since they are required to be c-commanded by DP antecedents within the same clause.

${ }^{9}$ We take note of the fact that the third person pronouns (o/e) could refer to Azima/Abanga or someone else, which could be Baako/Azure. This, we assume is triggered by the shift in role that discussed above. 
In the semantic domain, intensifiers always induce prominence/emphasis, a property that is not coded by their reflexives counterparts. Though the possible correlation between reflexives and intensifiers has been an attractive field of research for some time now, no research is available in this domain in the Mabia (Gur) languages of Ghana (West Africa) to our kowledge. This study is, therefore, important as it fills a gap in our knowledge about self-intensifiers and reflexive pronouns in Gurene and Dagbani, an area of the Mabia languages that has not been explored. However, the prosodic properties of the emphatic intensifiers and an elaboration on the intensifiers' information-structural marking, and how these affect their interpretation is not considered, and hopefully this is a potential area for future research.

List of abbreviations used in this paper

\begin{tabular}{|c|c|c|c|}
\hline 1 & $=$ first person & IMP & $=$ imperfective aspect \\
\hline 2 & $=$ second person & INAN & $=$ animate \\
\hline 3 & $=$ third person & INT & $=$ intensifier \\
\hline A & $=$ answer & NEG & $=$ negative morpheme \\
\hline ANIM & $=$ animate pronoun & NP & $=$ noun phrase \\
\hline CONJ & $=$ conjunction marker & PFV & $=$ perfective aspect \\
\hline $\mathrm{COP}$ & $=$ copula & PL & $=$ plural \\
\hline C & $=$ complementizer head & PST & $=$ past tense marker \\
\hline $\mathrm{CP}$ & $=$ omplementizer phrase & $S G$ & $=$ singular \\
\hline DEF & $=$ definite marker & NP & $=$ tense phrase \\
\hline DGB & $=$ Dagbani & $*$ & $=$ ungrammatical sentence \\
\hline FOC & $=$ focus marker & $\#$ & $=$ contextually infelicitous \\
\hline GUR & $=$ Guren $\varepsilon$ & & structure \\
\hline
\end{tabular}




\section{References}

Acheampong, S. O. (2015). Reflexivisation in Likpakpaanl. (Unpublished M.Phil Thesis) University of Education, Winneba, Ghana.

Acheampong, O. S., Atintono, A. S., \& Issah, A. S. (2019).The morpho-syntactic characterization of Likpakpaanl Reflexive Pronouns. Journal of West African Languages (JWAL). Vol: 46(1): pp: 122-141.

Agbedor, P. K. (2014). The Syntax of Ewe Reflexive and Logophoric Pronouns. In Yankah, Kwesi, Kofi, K.Saah \& Nana Aba A. Amfo (Eds.). A Legon Reader in Ghanaian Linguistics. Barnbury, OX: Ayebia Clarke Publishers Limited. Pp: 51-64.

Atintono, S. A. (2004). A Morpho-syntactic study of the Gurene Verb. MPhil thesis, University of Ghana, Legon.

Atintono, S. A. (2013). The Semantics and Grammar of Positional Verbs in Gurens: A Typological Perspective. PhD (Linguistics), Dissertation submitted to the University of Manchester, UK.

Bendor-Samuel, J. T. (1971). Niger-Congo Gur. In: T. Sebeok \& J. Berry (eds.) Linguistics in Sub-Saharan Africa, 141-178. The Hague/Paris: Mouton

Blevins, J. (1996). Mokilese reduplication. Linguistic Inquiry, 27:523-30.

Bodomo, A. (1997). The Structure of Dagaare. Stanford: CSLI.

Bodomo, A. (2020). MABIA: Its Genesis, Geographical Spread, and some Salient Genetic Features. Pp: 5-34. In Adams, Bodomo, Hasiyatu Abubakari, and Samuel A. Issah (eds), A Handbook of the Mabia Languages of West Africa. Galda Verlag Press, Germany.

Carnie, A.. (2013). Syntax: A Generative Introduction. $3^{\text {rd }}$ edition. Oxford, UK \& Cambridge, USA: Wiley-Blackwell Publishing.

Chomsky, N. (1981). Lectures on Government and Binding. Berlin: Mouton.

Constantinou, H. (2013). On the meaning of Intensifiers. Proceedings of the 19th Amsterdam Colloquium Maria Aloni, Michael Franke \& Floris Roelofsen (eds.) pp: 91-98.

Constantinou, H. (2014). Intensifiers Meaning and Distribution. Thesis submitted in partial fulfilment of the requirements for the degree of Doctor of Philosophy in Linguistics. UCL.

Dakubu, M. E. K. (1996). A Grammar of Gurens. Legon: Language Centre

Eckardt, R. (2001). Reanalysing selbst. Natural Language Semantics, 944), 371-412.

Edmondson, J., \& Plank, F. (1978). Great expectations: an intensive self-analysis. Linguistics and Philosophy, 2, 373-413.

Faltz, L. M. (1977). Reflexivisation: a study in universal syntax. U.C. Berkeley Dissertation. Reprinted 1987, Garland, New York.

Gast, V. (2006). The Grammar of Identity. Intensifiers and Reflexives in Germanic languages. NewYork: Routledge.

Givòn, T. (1976) Topic, pronoun and grammatical agreement. In Subject and Topic, Charles Li (ed.), 149-188. London/New York: Academic Press.

Harrison, S. P. (1973). Reduplication in Micronesian languages. Oceanic Linguistics 12:407-54.

Haspelmath, M. (2019). Comparing reflexive constructions in the world's languages. Ms. MPI-SHH Jena \& Leipzig University, Germany.

Hermon, C.-T. and Huang, J. [eds.] (2001). Long Distance Reflexives New York: Academic Press [Syntax and Semantics 33]

Huang, C.-T. J. (2002). "Distributivity and Reflexivity," in Sze-Wing Tang and Luther Liu (eds.) On the Formal Way to Chinese Languages, CSLI and Cambridge University Press, 2002; also in Nobuko Hasegawa (ed.), Proceedings of the Center of Excellence International Symposium, Kanada University, Japan.

Huddleston, R. and Pullum, G. K. (2002). The Cambridge Grammar of the English Language. Cambridge: Cambridge University Press.

Issah, A. S. (2011a). Reflexive pronouns in Dagbani. Legon Journal of the Humanities (LJH) Vol: 22, pp: $129-146$.

Issah, A. S. (2011b). The phonology of Dagbani verbal reduplication. Journal of West African Languages (JWAL) Vol: 38 (1): pp: $39-54$. 
König, E. (1991). The Meaning of Focus Particles. A Comparative Perspective. London: Routledge.

Konig, E. \& Siemund, P. (2000). Intensifiers and reflexives- a typological perspective. In Frajzyngier \& Curl 2000 , 41-74.

König, E. (2001). Intensifiers and reflexives. In M. Haspelmath, E. König, W. Oesterreicher, \& W. Raible (Eds.), Language Typology and Language Universals -An International Handbook of Contemporary Research (pp. 747-760). Berlin \& NewYork: Mouton.

König, E., Siegmund, P. \& Töpper, S. (2005). Intensifiers and reflexives. In Martin Haspelmath, Matthew S. Dryer, David Gil \& Bernard Comrie (eds.), The world atlas of language structures, xxx. Oxford: Oxford University Press .http://wals.info/chapter/112.

König, E., Siegmund, P. \& Töpper, S. (2013). Intensifiers and Reflexive Pronouns. In: Dryer, Matthew S. \& Haspelmath, Martin (eds.) The World Atlas of Language Structures Online. Leipzig: Max Planck Institute for Evolutionary Anthropology. (Available online at http://wals.info/chapter/47, Accessed on 2018-04-06.)

Moravcsik, E. (1972). Some cross-linguistic generalizations about intensifier constructions. In Proceedings of CLS 8 (pp. 272-277).

Naden, T. \& Schaefer, R. (1973). The Meaning of 'Frafra . Research Review. 9: 2, 5-12.

Naden, A.J. (1988). The Gur languages. The languages of Ghana, M. E. Kropp Dakubu (ed), 12-49. London: Kegan Paul International for the International African Institute.

Naden, A.J. (1989). Gur. The Niger-Congo languages, John T. Bendor-Samuel, (ed)141-168. Lanham, Maryland: University Press of America.

Nsoh, A. E. (1997). Some Aspects of Gurune (Frafra) Word-Structure. Unpublished MA Thesis. Department of Linguistics, University of Ghana, Legon.

Nsoh, A. E. (2002). "Classifying the Nominal in the Gurene Dialect of Farefare of Northern Ghana." Journal of Dagaare Studies, 83-95.

Nsoh, A. E. (2010). Adjective Types in Farefari. In Dakubu, M.E.K., Nana Aba Amfo, E. K. Osam, K. K. Saah and G. Akanlig-Pare Studies in the Languages of the Volta Basin 6;113-132.

Nsoh, A. E. (2011). A lexical-functional syntax of the adjective in the Farefari Language, PhD thesis, University of Ghana, Legon.

Olawsky, K. J. (1999). Aspects of Dagbani “ Grammar - with special emphasis on Phonology and morphology, Ph.D. dissertation; Munich, Lincom.

Osam, E. K. (2002). Reflexive marking and related functions in Akan. Journal of Asian and African Studies, 64, 1845.

Pica, P. (1985). Subject, Tense and Truth: Towards a Modular Approach to Binding in J. Guron, H. G. Obenauer, and J-Y. Pollock (Eds.), Grammatical Representation. Foris, Dordrecht, 259-291.

Pica, P. (1987). On the Nature of the Reflexivisation Cycle. NELS, 17:483-499.

Saah, K. K. (2014). Reflexive marking and interpretation in Akan. In Yankah, Kwesi, Kofi, K.Saah \& Nana Aba A. Amfo (Eds.) A Legon Reader in Ghanaian Linguistics. Barnbury, OX: Ayebia Clarke Publishers Limited. pp 37-50.

Siemund, P. (2000). Intensifiers: A Comparison of English and German. London: Routledge. Wang, L. (2011). Intensifiers and Reflexive Pronouns in English and Mandarin Chinese: A Contrastive Study, PhD (Linguistics), Dissertation submitted to the Freie Universität Berlin, Germany. 